Article

\title{
The English Version of the Multidimensional Inventory for Religious/Spiritual Well-Being (MI-RSWB-E): First Results from British College Students
}

\section{Human-Friedrich Unterrainer ${ }^{1,2, *}$, Oliver Nelson ${ }^{3}$, Joanna Collicutt ${ }^{3}$ and Andreas Fink ${ }^{2}$}

1 Centre for Integrative Addiction Research (Grüner Kreis Society), Rudolfsplatz 9, 1010, Vienna, Austria

2 Institute of Psychology, Karl-Franzens-University Graz, Universitätsplatz 2, 8010 Graz, Austria; E-Mail: andreas.fink@uni-graz.at

3 Heythrop College, University of London, Kensington Square, London W8 5HN, UK;

E-Mails: onelson65@gmail.com(O.N.); joanna.collicutt@hmc.ox.ac.uk (J.C.)

* Author to whom correspondence should be addressed; E-Mail: human.unterrainer@uni-graz.at; Tel.: +43-699-181-95-990.

Received: 6 June 2012; in revised form: 29 June 2012 / Accepted: 4 July 2012 /

Published: 10 July 2012

\begin{abstract}
In recent years there has been a steadily growing interest of religious/spiritual issues in several areas of psychology; a variety of reliable and valid means of assessing the different facets of religiosity/spirituality have been developed. However, there is still some need for multidimensional approaches. With respect to the positive experience with the German version of the Multidimensional Inventory for Religious/Spiritual Well-Being, we developed an English version of this scale (MI-RSWB-E) in order to facilitate research in this budding field. The MI-RSWB-E was tested and validated on a sample of British college-students $(n=400)$. First, the factor structure and psychometric properties of the MI-RSWB-E were analysed. As a second step, MI-RSWB-E dimensions were related to a variety of indicators of personality and mental health. An in-depth analysis provided evidence in support of the psychometric quality of the MI-RSWB-E, and the ability of its proposed six-factor structure. The MI-RSWB-E dimensions were also found to be substantially related to personality factors as well as with indicators of subjective wellbeing and mental illness. In light of these findings the MI-RSWB-E could be considered as a suitable tool in the assessment of different facets of religiosity/spirituality.
\end{abstract}


Keywords: personality factors; religiosity; spirituality; scale development; subjective well-being

\section{Introduction}

Over the past decade there has been a growing trend in determining what role, if any, religiosity and spirituality has in the context of personality and subjective well-being. For instance, Piedmont [1] proposed an extension of the Five Factor Model of personality traits by presuming a sixth factor named "Spiritual Transcendence". Moreover, Saroglou [2] reported a positive correlation between different parameters of religiosity and the Big-Five dimensions of Extraversion, Agreeableness and Conscientiousness. However, facets like Extrinsic Religiosity were found to be associated with higher scores on the Neuroticism dimension. Although religious/spiritual issues tended to be negatively related with different indicators of mental illness, in most cases, the exact nature of the relationship between religiosity/spirituality and mental health is presently not well understood and needs to be explored in much more depth. Thus, it has been rightly criticised that religious/spiritual issues are often taken for granted as a positive correlate of mental health in general [3]. Finding a clear-cut definition for religion or spirituality, which can fit all perspectives, can become an issue of controversy. Within the discipline of psychology of religion, Pargament [4] provides an increasingly influential definition (p. 32): "I define religion as a process, a search for significance in ways related to the sacred." Pargament argues strongly against the increasingly common tendency to split spirituality and religiosity into two distinct functions. A substantial number of psychometric measures, based on varying religious/spiritual backgrounds, have been developed for Anglo-American participants, as well as several scales for Europeans [5,6]. However, there is still a great demand for valid multidimensional measures to explore the different facets of religiosity and spirituality effectively.

The concept of "Spiritual Well-Being" was originally developed by Ellison and Paloutzian [7]. Subsequently other successful attempts were made to assess "Spiritual Well-Being" [8]. Based on this, the concept of Religious/Spiritual Well-Being (RSWB) was developed by an interdisciplinary clinical research group at the University Clinic in Graz, Austria. It was also the result of an attempt to expand the bio-psycho-social model with a religious/spiritual component [9,10]. A global definition of RSWB can be given as "the ability to experience and integrate meaning and purpose in existence through a connectedness with self, others or a power greater than oneself" [11]. As a first step, the difference between an immanent (bio-psycho-social) and a transcendent (religious-spiritual) field of perception was assumed; in the end an empirical model of RSWB, comprising six dimensions, could be established at the empirical level: Hope Immanent, Forgiveness, Experience of Sense and Meaning as parameters of well-being for the immanent area, Hope Transcendent, General Religiosity and Connectedness for the transcendent area. Dimensions such as Hope, Forgiveness, or Experiences of Sense and Meaning were always found to be substantially related to varying indicators of subjective well-being and might therefore be conceptualized as religious/spiritual dimensions as well as without any religious/spiritual connotation. The transcendent dimensions will require some further clarification: General Religiosity relates to a belief that is more institutionalised, bound to religious 
communities or traditions, whereas Connectedness is conceived as a more deinstitutionalized form of belief (e.g., someone who professes to be agnostic or simply spiritual). Hope Transcendent can be best described as the opposite of existential fear or the anxiety that people may exhibit towards death, for instance a belief in an afterlife that conforms to an idealised paradise. The whole list of the English items can be found in the Appendix enclosed herein. Furthermore, marker items are given as examples in order to illustrate the meaning of the different dimensions. General Religiosity: "My faith gives me a feeling of security"; Connectedness: "I have experienced the feeling of being absorbed into something greater"; Forgiveness: "There are things which I cannot forgive" (coded reversely); Experiences of Sense and Meaning: "I have experienced true (authentic) feelings"; Hope Immanent: "I view the future with optimism"; Hope Transcendent: "I often think about the fact that I will have to leave behind my loved ones" (coded reversely) [12].

The German MI-RSWB (MI-RSWB-G) was applied in several research projects and has been proven to display convincing psychometric properties [10]. Motivated by these promising results attained with the German version of the MI-RSWB, an English version of the scale was devised in order to facilitate research in this field for scientists beyond the German speaking countries. Here we present the first empirical results for the English version of the MI-RSWB (MI-RSWB-E) which were obtained in a sample of British college students. Based upon preliminary results it is hypothesised that the MI-RSWB-E shows similar factors and psychometric properties to the German original. For scale validation purposes, and also to discuss the concept within personality and health oriented research, dimensions of the MI-RSWB-E will be related to established measures for personality dimensions, subjective well-being and mental illness.

\section{Methods}

\subsection{Participants}

In total 400 British college students (200 females/ 200 males) between the ages of 18 and 63 years $(M=27.31, S D=8.87)$ were investigated. All participants were registered students at Heythrop College, University of London. The sole inclusion criterion was that the participants had English as their first language. $172(43.2 \%)$ of the respondents were single, $126(31.5 \%)$ were unmarried in a relationship, $74(18.5 \%)$ were married, 19 (4.8\%) were divorced, 8 (2\%) were widowed. 77 (19.2\%) had children. 175 (43.8\%) were Christian-Catholics, 105 (26.2\%) were Christian-Protestants, 37(9.2\%) were affiliated to another Christian religious community, $5(1.2 \%)$ were affiliated to another nonChristian religious community, 14 (3.5\%) seceded from church and $64(16.1 \%)$ were never affiliated to a religious community.

\subsection{Measures}

\subsubsection{Dimensions of Religious/Spiritual Well-Being}

The Multidimensional Inventory for Religious/Spiritual Well-Being (English) (MI-RSWB-E) consists in total of 48 items and six subscales (with eight items each). With respect to the German version, the total scale displays an internal consistency of $\alpha=0.89$ (Cronbach $\alpha$ 's for all subscales 
$>0.7$ ). The original version of this scale has been applied to different research contexts, where the RSWB-dimensions were found to be substantially related to different parameters of psychological well-being and personality among varying clinical and non-clinical samples [12,13]. The German version 108] was translated into the English language and re-translated into German by Austrian and British psychologists. Participants had to answer the 48 items of the MI-RSWB-E on a six-point rating scale ranging from 1 ("totally disagree") to 6 ("totally agree"). The MI-RSWB-E provides scores for six dimensions (i.e., Hope Immanent, Forgiveness, Experience of Sense and Meaning, Hope Transcendent, General Religiosity and Connectedness), which are measured with eight items each.

\subsubsection{Personality}

The Big Five Inventory 10 (BFI 10) [14] is a short version of the well-established BFI, which allows for the assessment of the big five dimensions of personality by means of only two items per dimension (in total 10 items). The BFI 10 has been shown to display psychometric properties that are highly commensurate to those of the total scale.

\subsubsection{Subjective Well-Being}

In a sub-sample of participants $(n=200)$ we also administered the Spiritual Well-Being Scale (SWB-S), which was originally developed by Ellison and Paloutzian [7], in order to measure the quality of the participants' spiritual health. In this context, Spiritual Well-being is conceptualised as a two-dimensional construct. On the one hand, Religious Well-Being describes, on a vertical axis, our well-being as it relates to God or even to a transcendent dimension. On the other hand, Existential well-being addresses, on a horizontal axis, our wellbeing as it relates to a sense of purpose and satisfaction with one's life, without any specific reference to a higher power.

\subsubsection{Mental Illness}

The Brief Symptom Inventory (BSI) [15] is a short version of the Short Symptom Checklist (SCL $90 \mathrm{R}$ ), a concise psychological self-report symptom scale which comprises 53 items. A psychometric evaluation of the BSI revealed that it is an acceptable alternative to the complete scale. Nine dimensions of psychiatric symptoms, namely Psychoticism, Hostility, Anxiety, Somatization, Phobic Anxiety, Anxiety, Paranoid Ideation, Depression and Obsessive-Compulsion can be measured. It is also possible to calculate a Global-Severity-Index (GSI) by summing up all the sub-scales. In addition, the Beck Depression Inventory (BDI) [16] was applied, which could claim the title of the most established instrument in this field for measuring the behavioural manifestations of depression. Many authors have pointed out the excellent properties of the 21 item-instrument for the purposes of research and therapy.

\subsection{Procedure}

The initial version of the MI-RSWB-E was tested on a sample of 400 students who were studying at Heythrop College, University of London. In addition, the dimensions of RSWB were related to different indicators of personality (in the total sample of the participants; $n=400$ ), subjective well- 
being (in a subsample of 200 students) and mental illness (in a subsample of 200 students) for an initial validation. Participants were either tested in small groups or were asked to fill in an online version of the survey. The psychometric tests were always administered in the same order as listed above. A testing session took approximately 60 minutes. The study protocol was approved by the Ethics Committee of Heythrop College, University of London.

\section{Results}

Mean and standard deviations (separately for both sexes) for all MI-RSWB-E sub-dimensions, as well as the total score, can be found in Table 1. All of the dimensions of MI-RSWB-E, except for Forgiveness, were found to be normally distributed. This was revealed by examining the skewness and the kurtosis of the raw score distributions of the MI-RSWB-E dimensions, along with tests for their goodness of fit (Kolmogorov Smirnov test). However, much like the German version, the dimensions of the MI-RSWB-E tended to be negatively skewed, indicating that individuals were more likely to agree to the items.

Table 1. Descriptive statistics of the English version of the Multidimensional Inventory of

Religious/Spiritual Wellbeing (MI-RSWB-E; $\mathrm{n}=400$ ).

\begin{tabular}{|c|c|c|c|c|c|c|c|c|c|c|c|c|}
\hline & \multicolumn{2}{|c|}{ Female $(n=200)$} & \multicolumn{2}{|c|}{ Male $(n=200)$} & \multicolumn{2}{|c|}{ Total $(n=400)$} & \multirow[b]{2}{*}{ Min } & \multirow[b]{2}{*}{$\max$} & \multirow[b]{2}{*}{ skewness } & \multirow[b]{2}{*}{ kurtosis } & \multicolumn{2}{|c|}{ Normal distribution } \\
\hline & $M$ & $S D$ & $M$ & $S D$ & $M$ & $S D$ & & & & & $z$ & $p$ \\
\hline GR & 28.60 & 13.72 & 27.83 & 13.50 & 28.22 & 13.60 & 8 & 48 & -0.13 & $-2.84 *$ & 1.28 & $>0.05$ \\
\hline FO & 35.60 & 8.00 & 35.08 & 9.12 & 35.19 & 8.57 & 9 & 48 & $-4.01 *$ & 0.14 & 2.23 & $<0.001$ \\
\hline HI & 33.95 & 6.32 & 32.95 & 6.94 & 33.45 & 44.14 & 14 & 48 & -2.17 & -0.93 & 1.06 & $>0.05$ \\
\hline $\mathrm{CO}$ & 29.75 & 8.88 & 28.28 & 8.96 & 29.01 & 8.95 & 8 & 48 & -1.75 & -2.28 & 1.35 & $>0.05$ \\
\hline SM & 38.98 & 5.90 & 37.95 & 6.84 & 38.46 & 6.40 & 13 & 48 & -1.76 & -0.103 & 1.45 & $>0.05$ \\
\hline HT & 32.23 & 7.77 & 32.34 & 6.841 & 32.28 & 7.80 & 8 & 48 & -2.23 & -1.23 & 1.31 & $>0.05$ \\
\hline RSWB & 198.80 & 32.98 & 194.42 & 3.31 & 196.60 & 33.68 & 98 & 282 & -2.38 & -2.52 & 1.24 & $>0.05$ \\
\hline
\end{tabular}

Note: $* p<0.01$. GR = General Religiosity; FO = Forgiveness; HI = Hope Immanent; CO = Connectedness;

$\mathrm{SM}=$ Experiences of Sense and Meaning; HT = Hope Transcendent; RSWB = Religious/Spiritual Well-Being;

$M=$ Mean; $S D=$ Standard deviation; $\min =$ minimum score; $\max =$ maximum score; ${ }^{\#}$ Kolmogorov-Smirnov-test.

In the next step of our investigation the inter-correlations between the dimensions of the MI-RSWB-E were computed. As shown in Table 2, the MI-RSWB-E dimensions displayed comparatively high correlations with the total score, and they were weakly to moderately correlated with each other with the exception of Hope Transcendent; that was revealed to have comparatively low correlations with the other dimensions. An explorative factor analysis with VARIMAX rotation (due to the theoretical presuppositions we limited the factors to be extracted to six) yielded a six-factor solution, accounting for $55.05 \%$ of the total variance. The strongest factor measured was General Religiosity (eigenvalue: $11.41 ; 23.77 \%$ explained variance), followed by Connectedness (eigenvalue: 4.41; 9.19\% explained variance), Meaning (eigenvalue: 4.07; 8.47\% explained variance), Forgiveness (eigenvalue: 2.56; 5.34\% explained variance), Hope Immanent (eigenvalue: 2.40; 5.00\% explained variance) and lastly Hope Transcendent (eigenvalue: $1.57 ; 3.27 \%$ explained variance). As shown in Table 2, satisfying internal consistencies (Cronbach's $\alpha$ ) were found for the MI-RSWB-E, a result which was similar to the German version of the scale $[10,11]$. 
Table 2. Internal consistencies (Cronbach's $\alpha$ ) and inter-correlations for the MI-RSWB-E subscales and the total scale.

\begin{tabular}{|c|c|c|c|c|c|c|c|}
\hline Dimensions & GR & FO & $\mathrm{HI}$ & $\mathrm{CO}$ & SM & HT & RSWB \\
\hline Item $n$ & 8 & 8 & 8 & 8 & 8 & 8 & 48 \\
\hline$\alpha($ MI-RSWB-E; $n=400)$ & 0.96 & 0.84 & 0.82 & 0.82 & 0.77 & 0.75 & 0.91 \\
\hline$\alpha($ MI-RSWB-G; $n=1500)$ & 0.94 & 0.84 & 0.84 & 0.77 & 0.76 & 0.72 & 0.89 \\
\hline General religiosity & - & $0.46 * * *$ & $0.19 * * *$ & $0.68 * * *$ & $0.38 * * *$ & 0.06 & $0.83 * * *$ \\
\hline Forgiveness & - & - & $0.18 * * *$ & $0.30 * * *$ & $0.28 * * *$ & $0.26 * * *$ & $0.67 * * *$ \\
\hline Hope immanent & & & - & $0.22 * * *$ & $0.37 * * *$ & 0.05 & $0.46 * * *$ \\
\hline Connectedness & & & & - & $0.54 * * *$ & 0.03 & $0.77 * * *$ \\
\hline Experiences of sense and meaning & & & & & - & 0.04 & $0.64 * * *$ \\
\hline Hope transcendent & & & & & & - & $0.35 * * *$ \\
\hline Total: Religious/Spiritual Well-Being & & & & & & & - \\
\hline
\end{tabular}

Note: $* * * p<0.001$; GR = General Religiosity; FO = Forgiveness; HI = Hope Immanent; CO = Connectedness;

$\mathrm{SM}=$ Experiences of Sense and Meaning; HT = Hope Transcendent; RSWB = Religious/Spiritual Well-Being.

Further illustration of the development of the MI-RSWB-E can be attained by using structural equation modelling for Confirmative Factor Analysis while inspecting Figure 1. Correspondingly, the MI-RSWB-E dimension Hope Transcendent exhibited a comparatively low association with the MI-RSWB-E total score. General Religiosity and Connectedness also turned out to be the strongest predictors for the total score of MI-RSWB-E.

The amount of RSWB was found to increase significantly with age $(r=0.26, p<0.001)$. Women appeared to exhibit somewhat higher religiosity/spirituality than men, although not significantly $(r=0.1$, $p=0.06)$. In Table 3 the correlations between the MI-RSWB-E dimensions and the Big Five personality factors are shown, along with the correlations for the MI-RSWB-E with different indicators of subjective well-being and mental illness. Substantial positive correlations between the MI-RSWB-E dimensions and personality were found with respect to Extraversion, Openness, Agreeableness and Conscientiousness (see Table 3). Specifically, there was a comparatively high positive correlation between the MI-RSWB-E dimension Forgiveness and Agreeableness. Also, Hope Immanent was observed to be substantially correlated with the personality dimensions Agreeableness and Extraversion and to a minor extent with conscientiousness. A similar pattern of results was found for the MI-RSWB-E dimension Experience of Sense and Meaning; this exhibited a comparatively strong correlation with the Big Five dimension openness. It is also noteworthy that there was a negative association between the total MI-RSWB-E score and Neuroticism (see Table 3).

Moreover, there were significant correlations between the total score of the Spiritual Well-Being scale (SWB-S) and all dimensions of the MI-RSWB-E, particularly with respect to General Religiosity, Forgiveness, Connectedness, and the total MI-RSWB-E score (see Table 3). Moreover, the SWB-S sub-dimensions Religious Well-Being and Existential Well-Being exhibited substantial correlations with the MI-RSWB-E dimensions (see Table 3). Indicators of Mental illness were mainly observed as being negatively associated with the MI-RSWB-E dimensions. As evident in Table 3, comparatively high correlations were observed for the MI-RSWB-E dimensions Hope Transcendent, Hope Immanent and Forgiveness (see Table 3). 
Figure 1. Factor loadings (standardized regression weights) together with several indices of model fit for MI-RSWB-E.

\begin{tabular}{|l|l|l|}
\hline Prelimimary AsS umptions & $\begin{array}{l}\text { Empirical model of dimensions of } \\
\text { Religious/Spiritual Well-Being (RSWB): The } \\
\text { total RSWB score consists of six sub- } \\
\text { dimensions: GREL = General Religiosity } \\
\text { CONN= Connectedness, MEANING } \\
\text { Experiences of Sense and Meaning, FORG } \\
\text { Forgiveness, HOPET=Hope Transcendent; } \\
\text { HOPEI = Hope Immanent. } \\
\text { RSWB = Religious/Spiritual Well-Being. }\end{array}$ \\
\hline Result
\end{tabular}

Table 3. Religious/Spiritual Well-being in relation to personality, subjective well-being and mental illness.

\begin{tabular}{lcccccccc}
\hline & $n$ & GR & FO & HI & CO & SM & HT & RSWB \\
\hline Personality factors & & & & & & & & \\
Extraversion & 400 & -0.06 & -0.02 & $0.20 * * *$ & -0.01 & $0.11 *$ & 0.08 & 0.04 \\
Neuroticism & 400 & -0.06 & -0.03 & -0.09 & -0.06 & 0.03 & -0.22 & $-0.14 *$ \\
Openness & 400 & -0.30 & -0.07 & -0.08 & 0.08 & $0.22 * * *$ & 0.01 & 0.02 \\
Conscientiousness & 400 & 0.07 & $0.12 *$ & $0.14 * *$ & 0.08 & $0.14 * *$ & $0.13 * *$ & $0.16 * *$ \\
Agreeableness & 400 & $0.17 * *$ & $0.28 * * *$ & $0.30 * * *$ & $0.14 * *$ & $0.19 * * *$ & $0.15 * *$ & $0.31 * * *$ \\
Subjective well-being & & & & & & & \\
Religious-Well-being & 200 & $0.80 * * *$ & $0.42 * * *$ & 0.05 & $0.54 * * *$ & $0.16 *$ & 0.11 & $0.65 * * *$ \\
Existential Well-being & 200 & $0.34 * * *$ & $0.37 * * *$ & $0.54 * * *$ & $0.17 *$ & $0.22 * * *$ & $0.20 * * *$ & $0.49 * * *$ \\
Spiritual Well-being & 200 & $0.75 * * *$ & $0.48 * * *$ & $0.31 * * *$ & $0.48 * * *$ & $0.22 * *$ & $0.16 *$ & $0.71 * * *$ \\
Mental illness & & & & & & & & \\
Depression & 200 & -0.09 & $0.26 * * *$ & $-0.35 * * *$ & -0.03 & -0.01 & $-0.31 * * *$ & $-0.26 * * *$ \\
Global Severity Index & 200 & -0.07 & $-0.28 * * *$ & $-0.33 * * *$ & 0.03 & -0.06 & $-0.42 * * *$ & $-0.25 * * *$ \\
\hline
\end{tabular}

Note: ${ }^{*} p<0.05$; $* * p<0.01$; ${ }^{* *} p<0.001$; GR $=$ General Religiosity; FO = Forgiveness; HI = Hope Immanent; $\mathrm{CO}=$ Connectedness; $\mathrm{SM}=$ Experiences of Sense and Meaning; HT = Hope Transcendent; RSWB $=$ Religious/Spiritual Well-Being. 


\section{Discussion}

In recent years the concept of Religious/Spiritual Well-being has been investigated vigorously, albeit by applying the German version of the MI-RSWB. In this context, the dimensions of the RSWB turned out to be substantially related with personality factors and with various indicators of subjective well-being and mental illness [12]. The newly adapted English version of this scale (MI-RSWB-E) shows a similar factor structure and psychometric properties with the German original [10]. Furthermore, as Table 3 reveals, substantial correlations were found between the MI-RSWB-E dimensions and personality factors as well as with indicators of mental health and illness. Corresponding to Saroglou [2], the Big Five personality dimensions Agreeableness and Conscientiousness turned out to be associated with the MI-RSWB-E, which parallels the results of the German version. However, somewhat contrary to our expectations, no correlation was found between Extraversion and the MI-RSWB-E. Moreover, analyses revealed a weak (negative) association between the RSWB and the personality dimension Neuroticism. In addition, the MI-RSWB-E sub-dimensions Hope and Forgiveness turned out to be strongly associated with indicators of subjective well-being (e.g., Existential Well-Being), which equals the results of MI-RSWB-G [10]. Contrary to our theoretical assumptions, Hope Transcendent was more strongly related to Existential Well-Being than to Religious Well-Being. The dimension Forgiveness was found to be substantially related to both Existential Well-Being and Religious Well-Being. General Religiosity and Connectedness were both found to be highly associated with Religious Well-Being. Thus, these two dimensions could be considered as two different kinds of belief systems. General Religiosity, in contrast to Connectedness, might be interpreted as being more strongly related to institutions, rites and traditions. Furthermore, in line with our assumptions, dimensions of MI-RSWB-E were found to be negatively associated with parameters of mental illness (see Table 3). Taken together, the findings of this study suggest that the English version of the MI-RSWB is equivalent to the MI-RSWB-G and might be considered as a reliable and valid tool for the assessment of different facets of religiosity and spirituality in personality and health oriented research.

There are several limitations which should be noted. First we administered the scales in two different ways: singly and in groups. However, controlling for test setting yielded no relevant result. It should also be mentioned that Heythrop College has an explicit religious/spiritual background as a Jesuit institution primarily devoted to the study of theology and philosophy. Thus, Heythrop students should not be seen as being representative of British students in general, since a higher degree of religiosity/spirituality amongst Heythrop students must be assumed. In this study we did not assess "ethnicity", which could be assumed to be rather important for future research; for instance, among religious minorities, there might appear specific kinds of RSWB that would differ from those brought up in a Western European culture. The MI-RSWB-G was developed based on an Abrahamic/monotheistic religious background. Still, it is a problem unsolved: how would the scale work when applied to polytheistic believers? Moreover, since Heythrop has a higher proportion of mature/post graduate students, the student body at Heythrop is considerably older than that of other universities. There was a tendency for women to score higher in RSWB, as a result there was a positive association between RSWB and gender. However, this gender effect comes across more clearly by applying MI-RSWB-G. All MI-RSWB dimensions, except "Forgiveness", were found to be 
normally distributed. We abandoned further transformations to gain artificial normal distribution. However, this point might be countered by adjusting the $\alpha$-level in further research. Moreover, inspection of Table 1 reveals that there might also be some "ceiling"-effects of "Forgiveness", especially in a highly religious population. As depicted in Figure 1, a poor model fit was achieved [17,18]. This mirrors the results for the German version and might be mainly caused by the "Hope Transcendent" sub-scale, which has consistently been shown to be the poorest predictor of the MI-RSWB total score. Future research might bring more insight as to whether this sub-scale should be included or not. However, at this point of test development we would like to keep it for the sake of completeness. In this paper we intended to present the first results for the English version of the MI-RSWB in a British university population; further research is needed to learn more about specific characteristics of MI-RSWB-E among various different populations.

By introducing the MI-RSWB-E to an English-speaking audience we hope to contribute to the continual development of this young and fledgling field of empirically oriented psychology of religion. As dimensions of religiosity and spirituality are becoming an increasingly important topic, there might be further applications for the MI-RSWB-E in clinical as well as non-clinical fields. In clinical surroundings the MI-RSWB-E might be useful as a diagnostic tool to evaluate the psychotherapeutic process, as for instance concepts of Hope or Forgiveness are becoming more and more recognised as important issues in psychotherapy [19]. In conclusion, the dimensions of religious/spiritual well-being were confirmed as forming a distinct research topic in the field of psychology of religion, but we would also like to suggest that there are possible links to the conceptual framework of Positive Psychology as well as research potential in Subjective Well-being [20]. Thus, further research within this broad conceptual background would be both highly desirable, and highly beneficial, for patients and counsellors alike.

\section{References and Notes}

1. Ralph L. Piedmont. "Does Spirituality Represent the Sixth Factor of Personality? Spiritual Transcendence and the Five-Factor Model.” Journal of Personality 67 (1999): 985-1013.

2. Vassilis Saroglou. "Religion and the five factors of personality: A meta-analytic review." Personality and Individual Differences 32 (2002): 15-25.

3. Richard P. Sloan, Emilia Bagiella, and Tia Powell. "Religion, spirituality, and medicine." Lancet 353 (1999): 664-667.

4. Kenneth I. Pargament. "The psychology of religion and spirituality? Yes and no." IJPR 9 (1999): $3-16$.

5. Peter C. Hill, and Ralph W. Hood. Measures of Religiosity. Birmingham, Alabama: Religious Education Press, 1999.

6. Jason M. Bredle, John M. Salsman, Scott M. Debb, Benjamin J. Arnold, and David Cella. "Spiritual Well-Being as a Component of Health-Related Quality of Life: The Functional Assessment of Chronic Illness Therapy-Spiritual Well-Being Scale (FACIT-Sp)." Religions 2 (2011): 77-94. doi:10.3390/rel2010077.

7. Craig W. Ellison. "Spiritual Well-Being: Conceptualization and Measurement." Journal of Psychology and Theology 11 (1983): 330-340. 
8. Barth B. Riley, Robert Perna, Denise G. Tate, Marty Forchheimer, Cheryl Anderson, and Gail Luera. "Types of spiritual well-being among persons with chronic illness: Their relation to various forms of quality of life." Archives of Physical Medicine and Rehabilitation 3 (1998): 258-264.

9. Human F. Unterrainer. Seelenfinsternis? Struktur und Inhalt der Gottesbeziehung im klinischpsychiatrischen Feld. Münster, New York, München, Berlin: Waxmann, 2010.

10. Human F. Unterrainer, Helmuth P. Huber, Karl H. Ladenhauf, Sandra J. Wallner, and Peter M. Liebmann. "MI-RSB 48: Die Entwicklung eines multidimensionalen Inventars zum religiösspirituellen Befinden [MI-RSWB 48: The Development of a Multidimensional Inventory for Religious/Spiritual Well-Being].” Diagnostica 2 (2010): 82-93.

11. Human F. Unterrainer, Karl H. Ladenhauf, Sandra J. Wallner-Liebmann, and Andreas Fink. "Dimensions of Religious/Spiritual Well-Being and their relation to personality and psychological well-being." Personality and Individual Differences 49 (2010): 192-197.

12. Human F. Unterrainer, Sandra J. Wallner-Liebmann, and Andreas Fink. "Different Types of Religious/Spiritual Well-Being and their relation to personality and psychological well-being." IJPR 2 (2011): 1-12.

13. Human F. Unterrainer, Helmuth P. Huber, Isabelle M. Sorgo, Joanna Collicutt, and Andreas Fink. "Dimensions of Religious/Spiritual Well-Being and Schizotypal Personality." Personality and Individual Differences 51 (2011): 360-364.

14. Beatrice Rammstedt. "The 10-Item Big Five Inventory (BFI-10): Norm values and investigation of socio-demographic effects based on a German population representative sample." European Journal of Psychological Assessment 23 (2007): 193-201.

15. Leonard R. DeRogatis, and Nick Melisaratos. "The Brief Symptom Inventory: an introductory report." Psychological Medicine 13 (1983): 595-605.

16. Aaron T. Beck, C. H. Ward, M. Mendelson, J. Mock, J. Erbaugh. “An Inventory for Measuring Depression." Archives of General Psychiatry 4 (1961): 53-63.

17. Li Hu, and Peter M. Bentler. "Cutoff criteria for fit indexes in covariance structure analysis: Conventional criteria versus new alternatives.” Structural Equation Modeling 6 (1999): 1-55.

18. Michael W. Browne, and Robert Cudeck. "Alternative ways of assessing model fit." Sociological Methods \& Research 21 (1992): 230-258.

19. Kenneth I. Pargament. Spiritually Integrated Psychotherapy: Understanding and Addressing the Sacred. New York: Guilford Press, 2007.

20. Robert A. Cummins. "Subjective Wellbeing, Homeostatically Protected Mood and Depression: A Synthesis.” Journal of Happiness Studies 11 (2010): 1-17. 


\section{Appendix}

\section{Instruction:}

Please keep the following in mind as you answer the questions:

1. You will find several questions concerning your religious/spiritual beliefs and you will often come across the term "God".

2. Your answers will only be used for research purposes and you will remain completely anonymous.

3. This study was not sponsored by a religious group and data will not (in their entirety or in part) be passed on to such organizations.

4. If you feel uncomfortable with the term "God", feel free to substitute it with a term you find suitable, such as "higher power" for example.

5. It is also possible to complete the questionnaire if you have agnostic or atheistic beliefs - the questionnaire takes such beliefs into consideration.

Please respond quickly and try not to take too long deliberating upon any one question. It is also important to answer each and every question; failing to respond to all the questions means that it will not be possible to evaluate the questionnaire correctly.

\section{List of Items}

\begin{tabular}{lll}
\hline Nr. & Dim. & \\
\hline 1 & GR & My faith gives me a feeling of security. \\
7 & GR & It is possible for me to find contentment in intimate conversations with God. \\
13 & GR & I will be able to overcome all problems with God's help. \\
19 & GR & In certain moments in my life, I feel very close to God. \\
25 & GR & With God's help, I will be happy once again. \\
31 & GR & I know that God is merciful. \\
37 & GR & I enjoy attending to religious community events. \\
43 & GR & I feel the presence of God in nature. \\
\hline 2 & FO & There are things which I cannot forgive.* \\
8 & FO & There are people whom I hate.* \\
14 & FO & There are people whom I will never be able to forgive.* \\
20 & FO & There are things which people should not forgive.* \\
26 & FO & If somebody hurts me, I usually try to get revenge.* \\
32 & FO & The thought of seeing my enemies suffer satisfies me.* \\
38 & FO & There are people who deserve to be treated badly.* \\
44 & FO & I have forgiven those people who have hurt me. \\
\hline 3 & HI & I view the future with optimism. \\
9 & HI & I think that things will improve in the future. \\
15 & HI & I think my life is moving in the right direction. \\
21 & HI & I think that I will have more positive than negative experiences in the future. \\
27 & HI & I think that I will live my life in the future just as I envisage it. \\
33 & HI & I have a precise picture of what my future should be like. \\
39 & HI & My future seems to be extremely uncertain.* \\
& &
\end{tabular}




\begin{tabular}{lll}
45 & HI & I believe that the future holds exciting challenges for me. \\
\hline 4 & CO & I have experienced the feeling of being absorbed into something greater. \\
10 & CO & I believe that I will be reborn after my death. \\
16 & CO & There are people with whom I feel a supernatural connection. \\
22 & CO & I have had experiences through which I have realized that nothing ever dies. \\
28 & CO & I believe in further existence after death. \\
34 & CO & I have experienced things which I cannot express in words. \\
40 & CO & I have experienced things which radiate a special kind of energy. \\
46 & CO & I believe that I will have experiences in the future to which very few people have access. \\
\hline 5 & HT & I often think about the fact that I will have to leave behind my loved ones.* \\
11 & HT & I would do anything to prolong the lives of those I love.* \\
17 & HT & It is hard for me to think that my loved ones will one day no longer live.* \\
23 & HT & I am terrified of being forgotten after my death.* \\
29 & HT & I would do anything to prolong my life.* \\
35 & HT & I am scared about what will happen to me after my death.* \\
41 & HT & All hope ends with death.* \\
47 & HT & I fear being made accountable for the things I have done wrong after my death.* \\
\hline 6 & SM & I have experienced true (authentic) feelings. \\
12 & SM & I have experienced deep affection. \\
18 & SM & I have experienced true friendship. \\
24 & SM & I have often experienced openness and honesty. \\
30 & SM & I have experienced things which I want to experience again and again. \\
36 & SM & I have often had experiences which have deeply affected me. \\
42 & SM & In my experience, it is possible for me to become so involved in something that I forget \\
48 & SM & I have had one or more experiences in which the meaning of life became clear to me. \\
\hline & & I
\end{tabular}

Notes: Nr.: Item number in the Questionnaire; Dimensions: GR = General Religiosity; FO = Forgiveness; $\mathrm{HI}=$ Hope Immanent; $\mathrm{CO}=$ Connectedness; HT = Hope Transcendent; $\mathrm{SM}=$ Experiences of Sense and Meaning. Likert scale: 1 : totally disagree -6 totally agree. Items marked with $*$ have be to coded inverse.

\section{Evaluation scheme}

\begin{tabular}{lc}
\hline Dimension & Item number \\
\hline General Religiosity (GR) & $1,7,13,19,25,31,37,43$ \\
Forgiveness (FO) & $2^{*}, 8^{*}, 14^{*}, 20^{*}, 26^{*}, 32^{*}, 38^{*}, 44$ \\
Hope Immanent (HI) & $3,9,15,21,27,33,39^{*}, 45$ \\
Connectedness (CO) & $4,10,16,22,28,34,40,46$ \\
Hope Transcendent (HT) & $5^{*}, 11^{*}, 17^{*}, 23^{*}, 29^{*}, 35^{*}, 41^{*}, 47^{*}$ \\
Experiences of Sense and Meaning (SM) & $6,12,18,24,30,36,42,48$ \\
\hline
\end{tabular}

Notes: $*=$ coded inverse.

(C) 2012 by the authors; licensee MDPI, Basel, Switzerland. This article is an open access article distributed under the terms and conditions of the Creative Commons Attribution license (http://creativecommons.org/licenses/by/3.0/). 